\title{
Multi-dimensional Perception of Parental Involvement
}

\author{
Yael Fisher \\ Department of Educational Administration, Achva Academic College, Israel
}

Copyright (C) 2016 by authors, all rights reserved. Authors agree that this article remains permanently open access under the terms of the Creative Commons Attribution License 4.0 International License

\begin{abstract}
The main purpose of this study was to define and conceptualize the term parental involvement. A questionnaire was administrated to parents (140), teachers (145), students (120) and high ranking civil servants in the Ministry of Education (30). Responses were analyzed through Smallest Space Analysis (SSA). The SSA solution among all groups rendered a two dimensional solution with a coefficient of alienation .18. The SSA map clearly divided 44 parental activities into four quadrants. The left and right regents represent the focus of parental activity: The left regent represents in-school activities and the right side represents out-school activities. The upper and lower regents represent the organizational level: The upper regent represents organizational based activities and the lower regent represents student-based activities. The initial findings also demonstrated that parental involvement can be defined by the 44 actions, which are deployed on the SSA map in a polarized facet. The facet includes four elements (separation index 1.00): Resources, school welfare, control processes and pedagogical and wellbeing contents. We now have a better understanding of what constitutes school-related parental involvement; we know that it reflects a broad spectrum of parental actions and activities, which can take place either at school or outside the school. The involvement can be expressed actively or passively, often relating to the school as an organization and often in the personal context of one's own child.
\end{abstract}

Keywords Parental Involvement, Elementary Schools, Facet Theory, Israel

\section{Theoretical Background}

Students whose parents are more involved have higher school grades than do their peers. This constitutes a good enough reason to encourage parental involvement [1,2]. However, in order to understand how parental involvement helps, and to encourage parents to get involved (and schools to promote parental involvement), the term parental involvement needs clarification.

In the past few years, the question of whether teachers, parents, students, and administrators share the same opinion about the definition and scope of the term "parental involvement" has been raised. On the one hand, it may seem that there is nothing controversial about it, since it is considered socially desirable to encourage parents' to become involved in their children's education. On the other hand, however, deeper research into the term and a variety of educational studies revealed that the term is vague and has many interpretations. The more traditional conceptualizations of the term refer to parental activities such as helping their children do homework assignments and frequently attending school functions $[3,4]$. Some define the term as a spectrum, whereby desired parental involvement can range from baking cakes for school events to supporting and operating self-managed schools. The more recent approaches suggest that parental involvement or parental engagement should refer to more subtle social variables, such as parental expectations and the quality of parent child communication $[5,6]$.

The professional literature has described Parental Involvement as including home behaviors as well as school behaviors. In fact, several researchers have defined parental involvement based on the location where the activity takes place, whether at home, at school, or in the school community $[7,8]$.

Some researchers have claimed that the direct cause for students' high scholastic achievements is parental involvement confined to the home, which includes discussions with the children about their experiences at school and about the importance of studying [9]. Others have claimed that it is parental involvement in the school that is the key to students' academic success $[10,11])$. Such results have been reported also in meta-analyses, such as those done by Jeynes $[5,12]$ indicating that the relationship between parental involvement and students' achievements is statistically significant.

The various interpretations indicate that the term defies a single definition and, thus, merits further examination, in an effort to attain greater clarity, let alone reach a consensus among researchers [13].

\subsection{Defining the Facets of Parental Involvement}

Reviewing the literature on parental involvement in 
previous studies has led to the delineation and classification of the content areas that form a conceptual domain of parental involvement. Three content facets were distinguished in classifying parental involvement. They are described in the following sections.

\section{Facet A: Parents Activity Focus}

Facet A classifies parents' focus of activity, being either within school or without school. A within school focus refers to all school activities that parents could be involved in and are performed within the school's geographical borders, while an outside-school focus refers to all school activities that parents could be involved in and are performed outside the school's geographical borders, i.e. at the child's home or anywhere else except the school. Therefore, Facet A consists of two elements: a1 - in-school activities, and a2 outside-school activities. Consequently, Facet A may play an axial role in deploying the points on the SSA map, so the items on the SSA map will be spread on an imaginary axix ranging from within school activities to without school activities.

\section{Facet B: Organizational Level of Parental Activities}

This Facet classifies the organizational level at which the activities take place. Student-level activities signify activities that concern only the parent's child and are aimed towards individual, child-oriented activities. In contrast, organizational-level activities encompass a wider spectrum, since they are not targeted solely towards one's own child. They are directed towards the school as a whole, as an organization. This facet also consists of two elements: b1 student-level activities, and b2 - organizational-level activities. Thus, Facet B may also play an axial role in deploying the points on the SSA map, ranging from student level activities to organizational level activities.

\section{Facet C: Parents Activity Areas}

This Facet is an unordered facet, since it is not possible to prefer one parental activity to another. An unordered facet plays a role of deploying the variables in an angular (or polarized) form on the SSA map, and each sector represents an area of parental activity. The areas are:

c1 - Improvement of school resources

c2 - Control

c3 - Pedagogy and school wellbeing

c4 - School welfare

\subsection{Definitional Framework and the Mapping Sentence}

Facer Theory [20] provided the basis for the definitional framework for studying the conceptualization of parental involvement. A definition of parental involvement can be made possible by the use of a mapping sentence (see figure 1) which is the key tool in Facet Theory and links the facets being studied: the facet of the population under investigation (X - parents in this study), three content facets (A -Activity focus, B - Organizational level and C -Activity areas), and the range facet ( $\mathrm{R}$ - the extent to which the parent is involved).

The mapping sentence classifies the research observations and provides the basis for hypotheses regarding the empirical links between the observed variables.

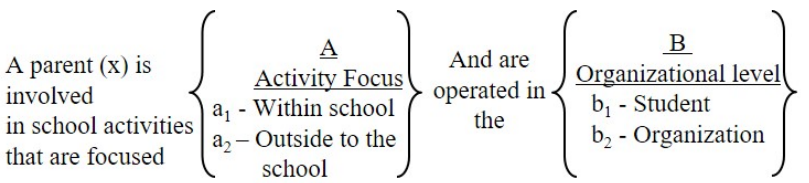

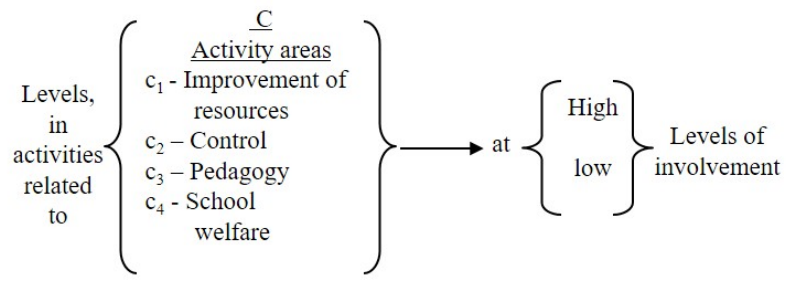

Figure 1. Mapping sentence for Observations on Parental Involvement Perception

\subsection{Explaining Facet Theory}

It was then decided to subject the data to a SSA (Smallest Space Analysis procedure, using the Hebrew University Data Analysis Program (HUDAP). Facet Theory is a unique approach used for research planning, data analysis and testing hypotheses regarding the relationship between the design of the research and its empirical results (Levy, 1994; Shye and Elizur, 1994). This theory was chosen as the methodological approach for the second level, due to its strength in conceptualizing different phenomena, and the fact that it does not rely on sample size. Facet Theory enables an integration of conceptual and empirical information in the search for rules or patterns that other scientific approaches cannot easily discern, especially where multivariate analysis is concerned. It also makes it possible to formulate a theory based on empirical findings. A theory according to Facet Theory is a hypothesis of correspondence between a definitional system for a universe of observations and an aspect of the empirical structure of those observations, and it includes the rationale for such a hypothesis [20 p. 335]. This strategy, which has been proven to be effective in establishing structural theories, does not define a concept like PSE in the conventional way. Rather, such a strategy enables us to think (of PSE) in terms of the collected observations of the concept, which in turn helps to address the problem of selecting the variables to be studied [20 p.336].

A central concept in Facet Theory is the facet. A facet is a classification of an issue under investigation, based on a common rule, enabling the grouping of components into a content unit or a single conceptual unit. SSA is a statistical model in which coefficients of proximity between variables (such as correlations or monotonicity coefficients) are represented as physical distances in a two- or 
multi-dimensional space. In this analysis, variables are shown as points in space, and the proximity between the points relates to the correlation between the variables: the greater the correlation, the closer the points in space. The spatial deployment picture (map) of the data that emerges using this method is easier to interpret than a correlation matrix, and it is used to establish associations between variables that other methods cannot reveal [21].

A polarized form means that each item in the facet's plot relates to a different direction in the geometric space. Thus, the points on the data distribution map will display as angular regions, each emanating from the same origin, fanning out, much like a pie chart. This type of distribution occurs when items in a facet are not organized by any particular order or rank. This is termed a polarizing facet. In the radial form, the graphic shape rendered by such data distribution is that of circular strips or concentric circles that share the same origin. A strip located closer to the origin features items with a higher degree of correlation between them than the correlation between items within a strip located farther from the point of origin. This form (i.e., concentric circles) has a hierarchically order organized according to levels of complexity. The spatial distribution of variables represents levels of complexity that decrease (in some cases increase) as we move from the point of origin towards the periphery. Thus, this type of facet modulates the location of items in terms of their distance from the source or origin, which is why it is termed a modulating facet [22].

The Radex pattern is a combination of polarizing and modulating aspects of item deployment. This pattern is found in many studies that examine phenomena that differ in terms of the amount or intensity of complexity, as well as in terms of qualitative features.

\section{Method}

\subsection{Subjects}

$\mathrm{N}=435$ : Civil servants in the Ministry of Education $\mathrm{N}=30$; teachers and principals $\mathrm{N}=140$; parents $\mathrm{N}=145$; and students $\mathrm{N}=120$.

\subsection{Instruments and Procedure}

This study used a questionnaire titled "Perceptions of Parental Involvement", which participants were asked to fill out. The questionnaire was administered using a different version for each group (civil servants, teachers, parents and students): 44 of the items on the questionnaire were identical and only the 12 background variables made it possible to distinguish the groups. Altogether, the questionnaire contained 56 items. Respondents were told that with the help of this questionnaire we intended to learn what they think parental involvement means in terms of real actions and activities. All items included active and passive activities pertaining to the relationship between parents and school and vice versa. Participants were asked to state the extent to which each of the items expressed their own beliefs and opinions. The instruments' items were formulated based on the findings of previous studies of Fisher \& Friedman [14,15] concerning parents' perception of parental involvement.

\subsection{Procedures}

The questionnaires were distributed directly to the teachers and school principals, parents, students and civil servants. The aim was to distribute 600 questionnaires in an attempt to reach a sample of 500 responders. However, only 435 questionnaires were completed ( $73 \%$ return rate).

\section{Results}

There were two levels of statistical processing. The first level involved computation of descriptive statistics, including means, variance, and item-total correlation for each item. The correlation matrix of the scale's item scores was subjected to factor analysis. The number of factors to be extracted was based primarily on the hypotheses presented in the mapping sentence. Factor analysis was intended to assist with first stage confirmation of the facet concerning the focus of parental activity. Kaiser's rule [16], Cattell's [17] scree test, and a comparison of the observed correlation matrix were used for verification. Internal consistency of the scale was measured using Cronbach's alpha coefficient. Cronbach's alpha coefficients for the scores in the whole scale (parental involvement) and the four subscales (enhancement of school resources, control, pedagogy and school wellbeing and school welfare) were $.89, .80, .85, .92$, and .70 , respectively.

The second level included subjecting the data to an SSA (Smallest Space Analysis) procedure, using the Hebrew University Data Analysis Program (HUDAP) [18,19]. 


\subsection{Understanding Parental Involvement}

Data deployment was examined in a two-dimensional space. The results were tested first by applying the coefficient of alienation ${ }^{1}$. Item deployment of the SSA map was first assessed by a two-dimensional presentation. The coefficient of alienation of the two-dimensional presentation was .28, which may be considered slightly too high. It was therefore decided to examine the item deployment further, by raising the dimensionality to 3 (dimensionality $=3$ ). This dimensionality's coefficient of alienation was .18, presenting a good fit between the data in the correlation matrix and the graphic presentation of data deployment. HUDAP also enables the calculation and marking of the facets' spatial borderlines defined by the mapping sentence. The rationality coefficients (a measure of goodness of fit between observed and expected item spatial deployment) were 1.000 for all three facets. Based on the alienation and the rationality coefficients, reliable interpretation could be made quite confidently.

Figure 2 shows the Small Space Analysis solution for Facets A, B and C. The findings demonstrate a perfect fit between the empirical data and the estimated structure for all three Facets ((separation index $\left.{ }^{2}=1.000\right)$.

A. The upper right-hand section of the map contains items describing parental activities that pertain to improvement of school resources: e.g., "Being responsible for fundraising and collecting funds for the individual class" (Table 1: item 14).

B. The lower right-hand lower section of the map contains items which relate to parental activities that pertain to control of parents over school activities: e.g., "Visiting the school once a week" (Table 1: item 9).

C. The lower left-hand section of the map contains items, which relate to parental activities that pertain to pedagogy and school wellbeing: e.g., "Expressing an opinion on the amount of homework" (Table 1: item 10).

D. The upper left-hand section of the map contains items, which relate to parental activities that pertain to welfare of the school: e.g., "Choosing a school for the child" (Table 1: item 3).

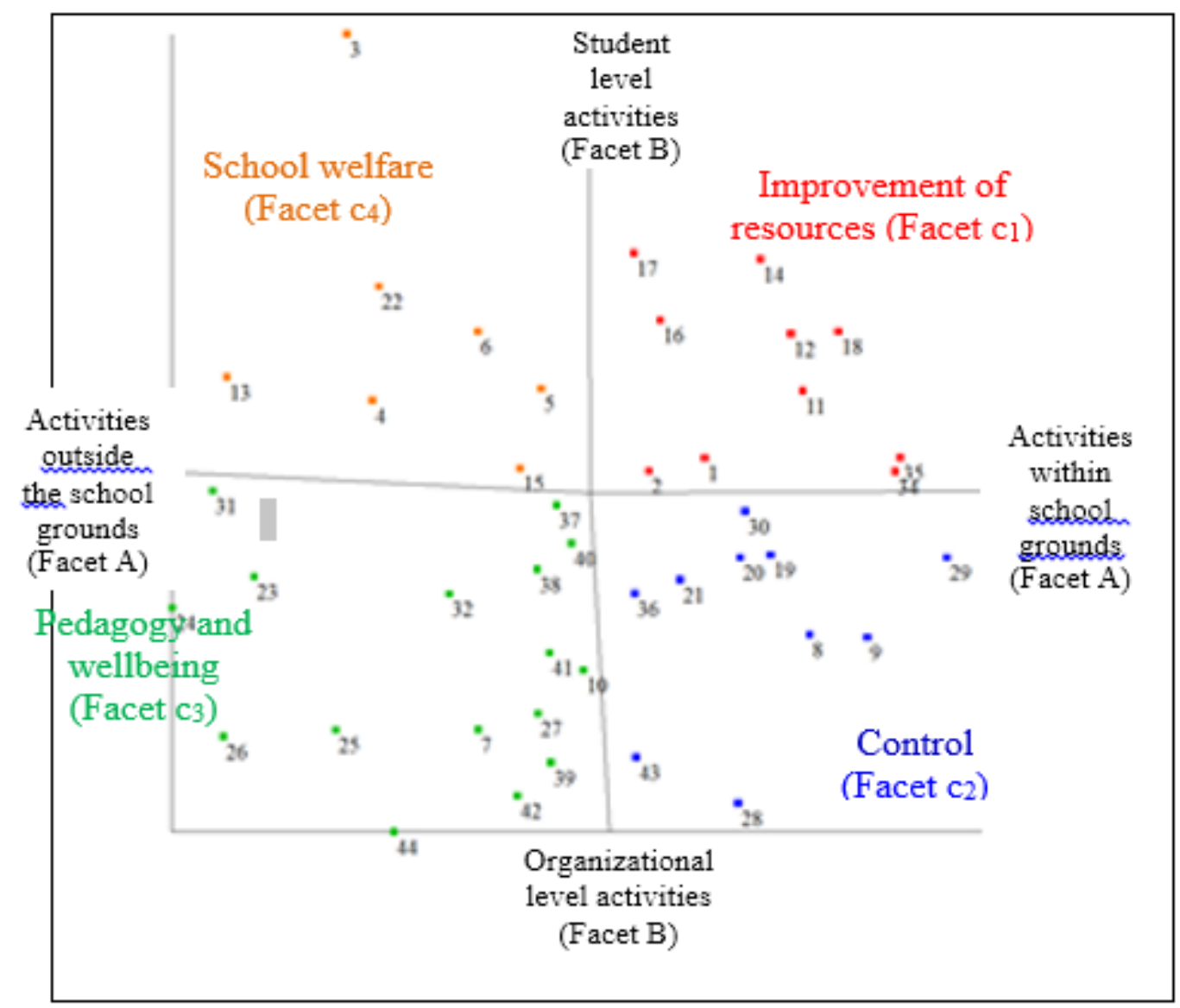

Figure 2. Definition of Parental Involvement: Deployment of Items on the SSA Map, Facets A, B and C (Dimensionality $=3$ )

1 The coefficient of alienation is a technical term which expresses the extent to which physical distances between items on the map accurately (in an inverse ratio) reflect the correlation between them. In other words, how well the software succeeded in "ordering" them graphically. The values range from $0-1$ such that the lower the value of the coefficient of alienation, the higher the fit.

2 The separation index denotes how far the empirical structure obtained reflects the hypothetical facet contents, i.e., the goodness-of-fit between the theoretical model examined and the spatial deployment of the empirical data on the SSA map. The separation index not only takes into account the number of items that "stray" from the predicted region, but also their distance from it, since it is based on the total distance between the real position of each point on the SSA map and the predicted position. Values range from $0-1$, with higher values being more desirable. 
Table 1. Questionnaire items Organized by Facet A, B and C

\begin{tabular}{|c|c|}
\hline Item No. & Item Content \\
\hline & $\begin{array}{l}\text { I think that parental involvement is.... } \\
\text { Improvement of school resources } \\
\text { Within school and at the organizational level }\end{array}$ \\
\hline 1 & Taking part in class PTA \\
\hline 2 & Taking part in school PTA \\
\hline 11 & Teaching in my child's class from time to time \\
\hline 12 & Creating and presenting activities for the whole school \\
\hline 14 & Fundraising for my child's class \\
\hline 16 & Fundraising for the school \\
\hline 17 & Giving a helping hand when needed \\
\hline 18 & Initiating informal activities \\
\hline 33 & Awareness of academic achievements \\
\hline 34 & Awareness of the decisions made by school management and staff \\
\hline 35 & $\begin{array}{c}\text { Conferring with the principal } \\
\text { Control } \\
\text { Within school and at the student level }\end{array}$ \\
\hline 8 & Visiting the class during the school day \\
\hline 9 & Visiting school once a week \\
\hline 19 & Taking part in pedagogical committees \\
\hline 20 & Curriculum development \\
\hline 21 & Criticism of the curriculum with staff and \\
\hline 28 & Familiarity with the teachers and school staff \\
\hline 29 & Awareness of the social activities carried out in the classroom and school \\
\hline 30 & Familiarity with the curriculum \\
\hline 36 & Participating in decision-making processes (class and school) \\
\hline 43 & $\begin{array}{l}\text { Perusing the exams after receiving the grade } \\
\text { Pedagogy and Wellbeing } \\
\text { Outside the school and at the student level }\end{array}$ \\
\hline 7 & Attending teacher-parent meetings \\
\hline 10 & Expressing an opinion on the amount of homework \\
\hline 23 & Hiring and firing of principals \\
\hline 24 & Placement of teachers in classes \\
\hline 25 & Intervention when there are inappropriate behaviors of teachers \\
\hline 26 & General Criticism of teachers \\
\hline 27 & Awareness of class social relations \\
\hline 32 & Awareness of school violence issues \\
\hline 37 & Assisting with homework \\
\hline 38 & Checking school notebooks \\
\hline 39 & Intervention when there are discipline issues \\
\hline 40 & Preparing with the child for exams \\
\hline 41 & Supporting the child when he or she has disagreements with teachers \\
\hline 42 & Involvement in filing an appeal on a grade \\
\hline 44 & $\begin{array}{c}\text { Calling the teacher once a week } \\
\text { Welfare of the school } \\
\text { Outside the school and at the organizational level }\end{array}$ \\
\hline 3 & Choosing a school for the child \\
\hline 4 & Accompanying the child on field trips \\
\hline 5 & Organizing school fairs \\
\hline 6 & Assisting with class events (not connected to everyday schoolwork) \\
\hline 13 & Adopting a new immigrant (not necessarily from the child's class) \\
\hline 15 & Financing enrichment programs and special projects \\
\hline 22 & Hiring and firing of teachers \\
\hline
\end{tabular}




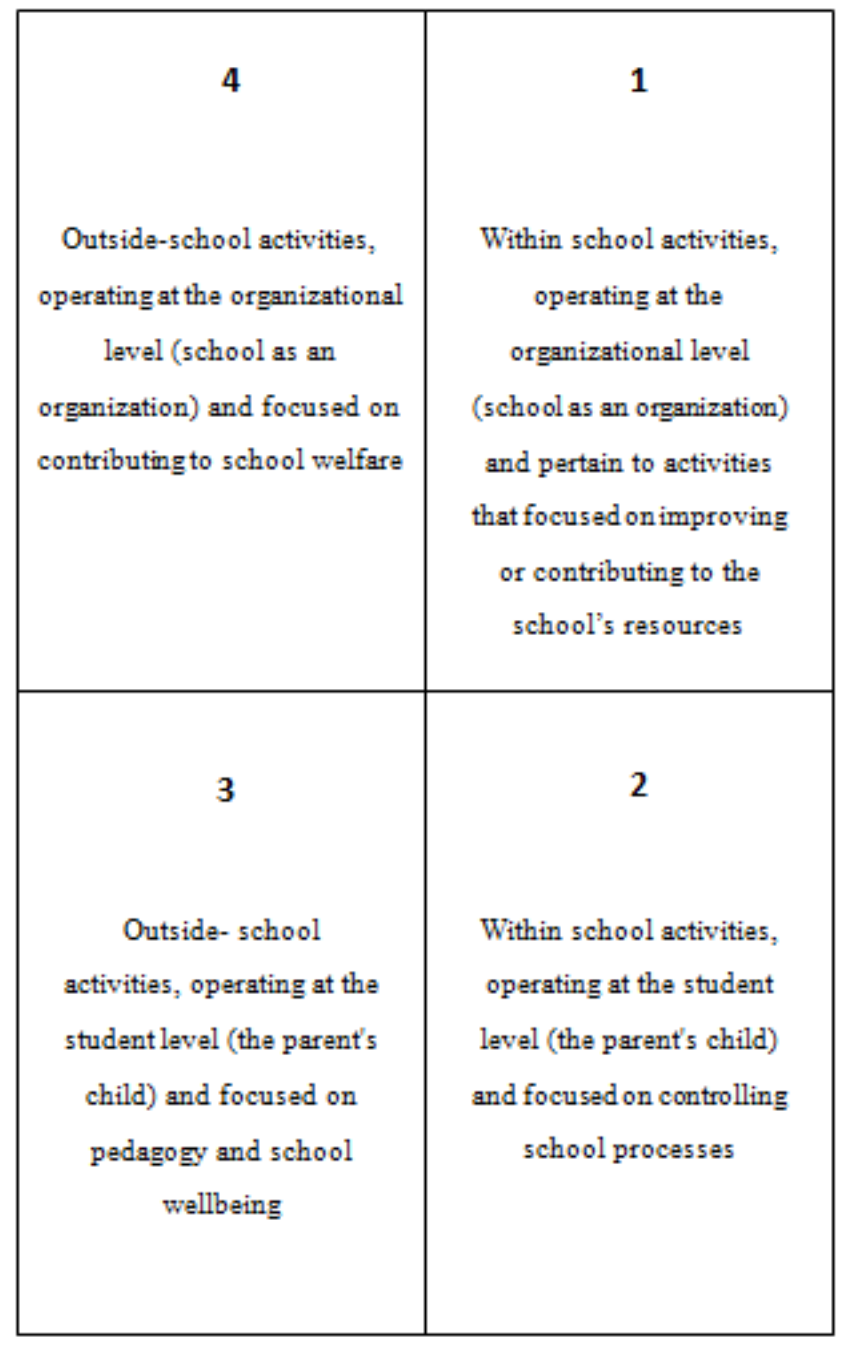

Figure 3. The contexture of parental involvement

\section{Conclusions}

Even though the professional literature has previously addressed the issue of parental involvement, including different attempts to define the term, as yet there has not been an attempt to conceptualize the term by investigating all stakeholders involved. Furthermore, no study has been done using Facet Theory for this purpose. Therefore, the main purpose of this study was to conceptualize the term parental involvement, as a term accepted by all those involved in the child's welfare and education at school. Traditional statistics such as factor analysis could have definitely showed the findings of Facet $\mathrm{C}$, the angular facet which divides parental involvement according to the focus of the activity. The current study found four main activity foci: i.e., activities that pertain to improvement of resources, activities that pertain to control over school procedures and outcomes, activities that pertain to pedagogy and wellbeing of the school and activities that pertain to the school's welfare. Thus, without using the Facet Theory approach we would not have been able to reveal the two other facets, representing the focus of the activity and the organizational level. These elements are not merely helpful; rather, they are essential if we wish to achieve a comprehensive understanding of the term.

This study fully supported the hypothesis that "parental involvement" in school reflects a broad spectrum of 44 activities, characterized by the focus of the parental activity (within school grounds or outside the school grounds), the organizational level (student level or organizational level) and focus of activity (improvement of resources, control, pedagogy and wellbeing and welfare). Bearing in mind that facets $\mathrm{A}, \mathrm{B}$ and $\mathrm{C}$ are related, we can now understand that a parent may be involved in 44 school activities, according to the four following groups seen in Figure 3 (Starting at 1 and continuing clockwise):

One should understand that this contexture does not emphasize any preference of one activity over the other. A parent could be involved simultaneously in all four groups, based on personal preferences, the school's preferences, or a combination of the two.

No topic about school improvement has generated more rhetoric than "parental involvement". Everyone agrees that it is important. In study after study, teachers, parents, administrators and even students from elementary school through high school claim that parental involvement benefits the students, improves schools, assists the teachers and strengthens families. Yet, there is confusion and disagreement about which practices are to be considered parental involvement. This study is an important breakthrough in the conceptualization of the term and makes progress towards reaching consensus. It also enables us to have a better understanding of family and school relations in the following areas:

1. Separate responsibilities of families and schools.

2. Shared responsibilities of families and schools.

3. Sequential responsibilities of families and schools.

With the support of this study, we can now claim that the term "parental involvement" in schools reflects a broad spectrum of parental actions and activities focused on various issues and conducted at within and outside school grounds. Involvement can be expressed actively or passively, in the context of school as an organization and in the context of the parent's individual child.

Having a better understanding of what "parental involvement" encompasses enables the schools and parents to decide together where, how, when, or if at all, they want to be involved.

\section{REFERENCES}

[1] Y. Fisher. Excellence in education: Implementing a theoretical model, Studies in educational administration \& organization, Vol. 27, 31-54, 2007 (in Hebrew).

[2] P. Vassalo. More than grades: How choice boosts parental 
involvement and benefits children, 2000. Online availeble from: http://www.cato.org/pubs/pas/pa383.pdf.

[3] T. Domina,. Leveling the home advantage: Assessing the effectiveness of parental involvement in elementary school. Sociology of Education, Vol.78, 233-249, 2005.

[4] J. L. Epstein, M. G. Sanders, B. S. Simon, K. C. Salinas, N. R. Jansorn, \& F. L. Voorhis,. School, family, and community partnerships: Your handbook for action. Thousand Oaks, Corwin Press, Inc. 2002.

[5] W, Jeynes. A meta-analysis of the relation of parental involvement to urban elementary school student academic achievement. Urban Education, Vol. 40, 237-269, 2005.

[6] W Jeynes. The salience of the subtle aspects of parental involvement and encouraging that involvement: Implications for school-based programs. kTeachers College Record, Vol. 112, No. 3 747-774. 2010

[7] A.C. Barton, C. Drake, J.G. Perez, K. St. Louis, \& M. George . Ecologies of Parent Engagement in Urban Education. Educational Researcher, Vol. 33, No.4, 1-1, 2004.

[8] J. Smith, P. Woblstetter, C.A. Kuzin, \& K. De Pedro. Parent involvement in urban charter schools: New strategies for increasing participation. The School Community Journal, Vol. 21,No. 1, 71-94. 2011

[9] M. Ingram, R. Wolfe, \& J. Lieberman. The role of parents in high-achieving schools serving low income, at risk populations, Education and Urban Society, Vol. 39, No. 4, 479-497, 2007.

[10] K. V. Hoover-Dempsey, J. M. T. Walker, K. P. Jones \& R.P. Reed.). Teachers involving parents (TIP): Results of an in-service teacher education program for enhancing parental involvement, Teaching and Teacher Education, Vol.18, No.7, 843-867, 2002.

[11] Y. Mo, \& K. Singh. Parents' relationships and involvement: Effects on students' school engagement and performance. Research in Middle Level Education Online, Vol. 31, No. 10, 1-11, 2008.
[12] W. Jeynes,. The relationship between parental involvement and urban secondary school student academic achievement: A meta-analysis, Urban Education, Vol. 42, 82-110, 2007.

[13] Y. Fisher, \& A. I. Friedman. Parents and school: Reciprocity and involvement, Dapim, Vol. 47, 11-40, 2009 (in Hebrew).

[14] A. I. Friedman, \& Y. Fisher. Parents and schools: Mutuality and involvement. Henrietta Szold Institute, National Institute for Research in the Behavioral Sciences, Israel, 2003 (in Hebrew).

[15] Y. Fisher \& A. I. Friedman. Identification and awareness: foundations for parental involvement in the school's functioning, Studies in Education Administration and Organization, Vol. 26, 6-33, 2002 (in Hebrew).

[16] J. C. Nunnally, \& I. H. Bernstein. Psychometric theory. McGraw-Hill, 1994.

[17] R.B. Cattell. The scree-test for the number of factors. Multivariate Behavioral Research, Vol.1, 245-276, 1966.

[18] I. Borg \& S. Shye. Facet Theory: Format and content. Sage Publication, 1995.

[19] S. Shye. Faceted SSA. A computer program for the PC. Jerusalem: Louis Guttman Israel Institute of Applied Behavioral Science Vol.7, 401-426, 1991.

[20] L. Guttman. What is not what in theory construction, in R.M Hauser, D. Mechanic \& A. Haller (Eds.), Social Structure and Behavior, Academic Press, pp. 331-348, 1982.

[21] A.I. Friedman. Facet theory: Principles and applications, in Y. Fisher, and I.A. Friedman, (Eds.), New horizons for facet theory: Interdisciplinary Collaboration Searching for Structure in Content Spaces and Measurement, FTA publication pp. 11-18, 2011.

[22] S. Levy. Lawful roles of facets in social theories, in D. Canter, (Ed.), Facet Theory: Approaches to social research, Springer Publication, pp. 59-96, 1985. 